\title{
Mídias sociais e radiodifusão comunitária como plataformas complementares
}

SOCIAL MEDIA AND COMMUNITY BROADCAST AS COMPLEMENTARY PLATFORMS

\section{Adilson Vaz Cabral Filho}

Professor associado da Universidade Federal Fluminense (UFF), atua no Departamento de Comunicação Social e nos Programas de Pós-graduação em Mídia e Cotidiano (PPGMC)

E-mail: acabral@comunicacao.pro.br

\section{Cinthya Pires Oliveira}

Mestranda do Programa de Pós-graduação em Mídia e Cotidiano (PPGMC) da Universidade Federal Fluminense (UFF).

E-mail: cinthyaoliveira@id.uff.br

Recebido em 6 de novembro de 2016. Aprovado em 8 de maio de 2017.

\section{Resumo}

Este artigo trata as mídias sociais como ferramentas complementares para articular pessoas em torno das iniciativas de comunicação comunitária. Problematizando o uso dessas mídias no ativismo comunitário e a construção de uma esfera pública política local nossa pesquisa, baseada em pesquisa bibliográfica, divide-se em três partes: 1) resistência da radiodifusão comunitária em tempos de convergência e mídia social como plataforma de complementaridade; 2) uso de mídias sociais nas iniciativas de radiodifusão comunitária; e 3) desafios futuros para o desenvolvimento de uma esfera pública política em torno de iniciativas de radiodifusão comunitária.

Palavras-chave: Comunicação comunitária. Mídias sociais. Esfera pública local. 


\section{Abstract}

This article examines social media as complementary tools to articulate people around community communication initiatives, Problematizing the use of these media in community activism and the building of a local political public sphere, our research, based on bibliographic research is divided in three parts: 1) community broadcasting resistance in times of convergence and social media as platforms of complementarity; 2) use of social media in community broadcasting initiatives; and 3) future challenges for developing a political public sphere around community broadcasting initiatives.

Keywords: Community communication. Social media. Local public sphere.

\section{Introdução}

O foco deste trabalho é o uso complementar das mídias sociais por iniciativas da comunicação comunitária, sendo que esta lida diretamente com o uso do espectro eletromagnético regulado pelos Estados-nações, com implicações políticas e legais em um cenário de convergência transmidiática em ambientes multiplataforma. Apesar da expansão da internet em escala considerável, a partir de atributos como armazenagem de dados, banda larga, mídias sociais e mobilidade, não há motivos que inviabilizem a atuação no território da radiodifusão pelas ondas eletromagnéticas, visto que se trata de uma área ainda em disputa e compreendida como determinante na conformação da esfera pública.

A baixa potência reivindicada na maioria das legislações que mencionam o setor comunitário nas comunicações incide na articulação e reorganização do local. O contexto evidencia a limitação do ambiente da internet na conformação de iniciativas articuladas e duradouras para além das mobilizações fragmentadas e pontuais, recorrentes no cenário contemporâneo. A mídia tradicional também atua significativamente na deslegitimação e estigmatização das iniciativas comunitárias de comunicação junto à sociedade, contribuindo para desprestigiá-las e reduzindo as possibilidades de atuação e propagação dessas iniciativas, autônomas e descomprometidas, ao que permitem as tecnologias da internet.

No entanto, apesar de as novas tecnologias da informação (NTICs) ampliarem seu contingente populacional, estas não alcançam a sociedade de modo mais abrangente, principalmente em locais distantes de grandes cidades, ainda majoritariamente referenciadas na mídia convencional. Afirma-se, portanto, a importância da radiodifusão comunitária no reforço das articulações locais que facilitem a construção das ações políticas 
contínuas, bem como dialoguem com o conjunto da sociedade que ainda tem na mídia tradicional um interlocutor privilegiado.

A partir dos anos 1970, com o barateamento dos equipamentos de produção e transmissão, as iniciativas comunitárias de comunicação em rádio e TV se tornaram mais desejadas, estimuladas e empreendidas por grupos organizados em todo o mundo, tornando-se evidente, para autores como Santoro (1989, p. 113), a contribuição "para que as classes populares possam expressar a sua própria visão de mundo, informar-se, registrar sua história".

Àquela época, os desafios eram maiores e mais limitantes para a sociedade em geral e grupos diretamente envolvidos com o ativismo midiático. Era determinante a necessidade de criar fluxos alternativos de circulação de conteúdos audiovisuais, contrários à hegemonia imposta pelos grupos políticos e empresariais, incluindo os próprios grupos de mídia corporativos, ou Estados que não estimulavam a diversidade de produção e circulação de conteúdo em suas emissoras. Além de seu caráter popular, tais iniciativas eram diretamente apropriadas pelas populações locais ou contavam sempre com o envolvimento de grupos de apoio oriundos de universidades, sindicatos ou movimentos sociais.

Não à toa, as denominações que designavam essas experiências apontavam algumas características como determinantes dessas iniciativas de comunicação, dentre elas: alternativa, contra-hegemônica e popular (PERUZZO, 2006), identificando o que a Unesco já indicava como irreversível desde seu conhecido Relatório MacBride (1980): "indivíduos e grupos podem (ou poderão proximamente) utilizar os seus meios de comunicação e recursos próprios, ao mesmo tempo que os dos meios de comunicação social".

Ao longo dos anos 1980 e 1990, as iniciativas comunitárias de comunicação possibilitaram a apropriação social de equipamentos e processos autônomos de produção em práticas distintas, por parte de grupos populares, movimentos e organizações, e assessoria à produção por parte de grupos de apoio, constituídos através de meios sociais e acadêmicos. Expandiram-se e se fortaleceram no embalo da própria conformação do assim chamado terceiro setor, sendo a expressão "privado, porém público" acolhida tanto no meio social quanto no acadêmico que a reconhecia.

Rádios e TVs comunitárias, associativas e livres se espalharam, buscando incentivar a capacidade de produção e veiculação de conteúdos alternativos à mídia hegemônica. Não se tratava apenas da apropriação de meios, mas da compreensão de seu uso para enfrentar questões várias que sempre foram postas a movimentos sociais e políticos em diferentes contextos. O barateamento das tecnologias permitiu o desenvolvimento de produtos, estéticas e diálogos nos meios sociais, levando à compreensão de que a sociedade e seus grupos constitutivos não se viam representados na mídia hegemônica tradicional.

\footnotetext{
$68 \frac{\text { Comunicação \& Inovação, PPGCOM/USCS }}{\text { v. 18, n. } 37 \text { (66-83) maio-ago } 2017}$
} 
O desejo de ocupação do espectro não era consensual entre realizadores de vários contextos nacionais, na medida em que defensores do espaço público como forma de congraçamento popular não acreditavam e nem mesmo se mobilizavam pela ocupação da mídia tradicional em favor das dinâmicas que estabeleciam. Por outro lado, a compreensão de que as mídias criadas a partir da própria comunidade viabilizavam a produção e a circulação de conteúdos diversificados dos tradicionais, colocando-se numa perspectiva contra-hegemônica, fazia crescer a importância da luta pela democratização da comunicação para o fortalecimento das lutas mais gerais. No entanto, ainda partia-se do entendimento de que a comunicação consistia num meio para efetivar essa luta e que a atuação específica em torno desse setor demandava um envolvimento também específico, porém de construção ainda descolada de outras questões estruturais e de natureza social.

A maturação dessas experiências deu lugar ao desenvolvimento de associações locais, regionais e nacionais de ativistas em todo o mundo, articuladas a movimentos continentais e mundiais de iniciativas comuns que floresceram ao longo dos anos 1980, como a Videazimuth - Coalizão Internacional de Videastas Independentes, ou mesmo a Associação Mundial de Rádios Comunitárias (Amarc), criada em 1983. Muitas dessas experiências eram ligadas a movimentos e ONGs que se institucionalizaram ao longo dos anos 1990, levando à depreciação de iniciativas próprias e ao investimento na relação com meios massivos. Muitos investimentos na efetivação de meios próprios foram deslocados para ações mais diretamente relacionadas à inserção de conteúdos na mídia tradicional.

As poucas experiências efetivamente comunitárias fazem a diferença, mas sempre foram dificuldades a busca por formas de sustentação e o engajamento da população na programação e no apoio à produção. Na prática, ativistas seguem ainda levando adiante iniciativas comunitárias que demandam incentivos, estímulos, envolvimento, bem como regulamentação, regulação e fiscalização; até porque são, por excelência, a democratização da comunicação em termos de pluralidade, diversidade e apropriação por parte da sociedade constituída em suas organizações, a despeito das relações de mercado ou das estruturas de Estado.

Por outro lado, ao assumir tais atribuições, o Estado está longe de ter seu papel minimizado diante da necessidade crescente pela afirmação de outro setor para além do estatal e do privado, como defende Ramos (2007), na medida em que se trata justamente de fazê-lo assumir atribuições de formulação, aprovação, implementação, monitoramento, fiscalização das políticas públicas e mesmo fomento e capacitação para as iniciativas de comunicação comunitária. "Em outras palavras, que exerça plenamente um Poder que seja Executivo das políticas que aprova" (CABRAL FILHO, 2015, p. 20). 
Portanto, faz-se necessária uma análise sistêmica das comunicações comunitárias desenvolvidas nas diferentes plataformas, que permita sua articulação com estudos em torno da formulação de políticas públicas e sociais para o setor, seus sujeitos e iniciativas, buscando compreender a sociedade e os usos que esta faz dos meios de produção e transmissão da comunicação. No contexto de reflexões e posicionamentos a respeito das Políticas Nacionais de Comunicação, torna-se cada vez mais necessária a ênfase na regulação e regulamentação de um setor configurado com base no reconhecimento de sua condição distinta do Estado e do mercado, compreendendo assim os desafios para sua regulamentação e sustentabilidade, bem como demarcando sua distinção em relação aos âmbitos estatal e empresarial.

O caso brasileiro é bastante emblemático: o artigo 223 da Constituição Federal Brasileira (1988) tem a seguinte formulação: "Compete ao Poder Executivo outorgar e renovar concessão, permissão e autorização para o serviço de radiodifusão sonora e de sons e imagens, observado o princípio da complementaridade dos sistemas privado, público e estatal". Como não há regulamentação específica derivada desse artigo, não é possível compreender o significado exato de "complementaridade", nem sistemas distintos como parte de um serviço.

É recorrente também a reivindicação da descriminalização do exercício da comunicação comunitária no contexto de distintos países. Justamente a condição de negligência do setor por parte do Estado, tanto do ponto de vista da fiscalização, como da ausência de fomento e capacitação, proporciona o incentivo ao caminho da ilegalidade ou da desobediência civil como tentativa de viabilizar as iniciativas junto à comunidade. $\mathrm{O}$ que pode ser observado, ao longo desses anos, é a descrença e a deslegitimação dessas iniciativas por parte das populações nas localidades em que atuam, ao lado de uma reorientação para a busca de outras iniciativas de mobilização que não enfrentem problemas jurídicos ou mesmo econômicos, na compreensão de que a hegemonia construída pela mídia inviabiliza a persistência na articulação e na afirmação dessas iniciativas, num reconhecimento deliberado à exploração da mídia tradicional e à opressão às iniciativas autonomamente organizadas pelos grupos populares.

Nesse contexto entra a internet, articulada num ambiente constituído pela crescente disseminação da banda larga, possibilitando o uso pleno de suportes multimídia em tempo real, de mídias sociais por tecnologias móveis e, mais recentemente, geolocalizadas. Esse ambiente não oferece barreiras jurídicas para elaborar, implementar e manter iniciativas comunitárias de comunicação. Entretanto, se compreendido como alternativa à radiodifusão comunitária, acaba reforçando a disposição em abandonar o território de disputa da distribuição do espectro eletromagnético, regulamentado e regulado pelo Estado, 
sendo cada vez mais majoritariamente assimilado pelo setor privado com fins lucrativos em todo mundo, em especial as operadoras de telecomunicações, mesmo com variações de formato e intensidade.

\section{Iniciativas de radiodifusão comunitária nas mídias sociais}

Pelo exposto, devemos considerar a representação e a comunicação política desenvolvidas pelas iniciativas comunitárias com sua atuação na internet e, portanto, num espaço público desterritorializado, assim como seus efeitos sobre a rede e percepções dos internautas; pois comunicação pública é "política pública para a democratização do saber" (MATOS, 2009, p. 56). Conclui-se que o desenvolvimento e aperfeiçoamento das TVs e rádios comunitárias devem fundamentar o ideal de comunicação pública voltado para a pluralidade de espaços que garantam "a intervenção do cidadão no debate de questões de interesse público" (Ibid., p. 47).

Nesse caso, as mensagens emitidas pela comunicação comunitária devem viabilizar que os cidadãos interlocutores compreendam o tema discutido, consigam filtrar argumentos e estabelecer pensamento crítico; para que possam emitir opiniões e juízos baseados no uso da razão e consequente ação, contribuindo com os conteúdos e as atividades das iniciativas comunitárias e com os fluxos de comunicação estabelecidos. Eis o conceito de "ação comunicativa": ele não deve ser confundido com a imposição de argumentos fundamentada numa autoridade elitista; deve ser um projeto de contínuo aperfeiçoamento que faça os cidadãos comuns, homens ordinários, participarem do diálogo. Portanto, é necessário ampliarmos estudos sobre os processos de distribuição de mensagens pela radiodifusão comunitária como construção de espaços públicos de diálogo, avaliando a complementariedade e eventual contribuição das mídias sociais na construção do consenso e da efetivação do agir comunicativo.

Apesar da evolução nos números de acesso à internet e aumento da aquisição de dispositivos eletrônicos, sabe-se que o acesso à tecnologia muitas vezes é seletivo. No entanto, a atuação dos meios de comunicação comunitária local pode corroborar a disseminação de usos e apropriação social desses espaços, possibilitando que ocorram trocas e envolvimentos não somente com os veículos e respectivos conteúdos produzidos, como também compartilhamento de ações no desenvolvimento de mensagens.

Apesar da complexidade de variáveis que envolvem essas iniciativas, inclusive com influências políticas, ideológicas e econômicas, estamos interessados em avaliar o quanto as ações especificamente de TVs comunitárias, através das mídias sociais, podem estimular a população a se expressar e se relacionar com estes meios, garantindo sua 
apropriação popular e estabelecendo um espaço público propício para o diálogo. Ou seja, o objetivo é perceber quão participante e engajada a comunidade se mostra em ações comunicacionais concretas, apesar das construções históricas, sociais e culturais que ainda possam subjugar e renegar essas pessoas à passividade.

\section{TVs comunitárias e o uso das mídias sociais como espaço público de diálogo}

De acordo com os dados da pesquisa TIC 2014ㄹ, do Cetic, 50\% dos domicílios brasileiros apresentam conexão à internet, incluindo acesso através de dispositivos móveis. Já segundo a $15^{\mathrm{a}}$ edição da Pesquisa F/Radar ${ }^{2}$ - Democracia e Consumo, realizada entre 11 e 13 de março de 2015 em 144 municípios (2.226 entrevistas), 65\% da população brasileira acessa a internet, o que corresponde a 107 milhões de pessoas - destas, 87 milhões se conectam pelo celular.

Conforme o levantamento, as mídias sociais são relevantes para mobilização social: 45 milhões de brasileiros afirmaram já ter participado de movimentos sociais. Destes, 31 milhões participaram presencialmente, enquanto 27 milhões o fizeram pela internet (o que indica a sobreposição de 13 milhões atuantes em ambos espaços, físico e virtual), e a maioria desses participantes (presenciais ou virtuais) pertence às classes econômicas $\mathrm{B}$ e C.

A atuação em rede corrobora a disseminação de informações, o que também influencia a opinião pública. Os números indicam que sete em cada dez internautas brasileiros acreditam que as redes sociais contribuem para o diálogo sobre questões e problemas relacionados ao bairro, cidade ou país; e 58\% dos entrevistados afirmam que as mensagens divulgadas pelas mídias sociais contribuem para a mudança de opinião a respeito de algum problema social.

Esses dados também são reflexo do tempo dedicado às mídias sociais no país - o instituto de pesquisa $\mathrm{ComScore}^{3}$ relata que a média de minutos por visita em redes sociais é maior do mundo, sendo que $51 \%$ dos internautas usuários desses sites encontram-se na região Sudeste do Brasil, com destaque para São Paulo (29\%) e Rio de Janeiro (12\%); estados reconhecidos pelo potencial econômico e turístico, respectivamente. Do total de tempo gasto com mídias sociais, 97\% é direcionado ao Facebook, acessadopor 89 milhões de brasileiros todos os meses ${ }^{4}$.

1 Disponível em: $<$ http://www.cetic.br/>. Acesso em: 20 fev. 2016.

2 Disponível em: < http://www.fnazca.com.br/>. Acesso em: 20 fev. 2016.

3 Fonte: The state of social media in Brazil and the metrics that really matter (www.comscore.com/).

4 Fonte: Consultoria EMarKeter. Disponível em: <www.meioemensagem.com.br>. Acesso em: 20 fev. 2016. 
Diante do exposto, as ações comunicativas das TVs comunitárias nas mídias sociais, como espaço complementar de diálogo com a população, deve ser alvo de análise. por meio de dados da Frente Nacional pela Valorização dasTVs do Campo Público (Frenavatec) e da Associação dos Canais Comunitários do Estado de São Paulo (Acesp), foram identificados 89 canais comunitários no Brasil, com concentração nas regiões Sudeste (65\%) e Sul (17\%), seguidas do Nordeste (10\%), Centro-Oeste $(6 \%)$ e Norte (2\%). Com esse mapeamento, foi realizada uma análise exploratória prévia para identificar as formas de utilização das mídias sociais de modo complementar pelos 89 canais comunitários de TV na internet.

Apesar das limitações tecnológicas, pelos dados expostos não podemos negar a importância da internet no cenário comunicacional do país no que diz respeito às relações sociais. Mesmo no Norte do país - onde há dois canais comunitários, um deles, a TV Cidade (Manaus/AM) -, utiliza os recursos tecnológicos e as redes sociais de modo a intensificar a relação com a sociedade; questão que deve ser aprofundada posteriormente. Na região Sudeste, apesar da maior concentração de TVs comunitárias e disseminação de NTICs, observamos discrepâncias em suas formas de utilização e no modo como essas emissoras atuam nas mídias sociais.

Assim, cabe atentarmos para o fato de que, a despeito das diferenças históricas, culturais, sociais, políticas e econômicas que delineiam o cenários das cinco regiões brasileiras, as discrepâncias refletidas no agir comunicacional ocorrem em regiões geográficas mais próximas, dentro do mesmo estado federativo, por exemplo. Confirmamos que, apesar das supostas facilidades no uso das mídias sociais, os desafios e as realidades são tão distintas quanto nos processos de radiodifusão comunitária.

Para exemplificar, apresentaremos informações coletadas sobre duas cidades do estado do Rio de Janeiro, com 30 quilômetros de distância entre ambas, e de características socioeconômicas muito distintas, que traduzem abismos sociais. Assim, ao longo do mês de janeiro de 2016, analisamos interações da população com TVs comunitárias nas mídias sociais. Realizamos observação virtual referente ao nível de "interação bruta" identificada nas ações on-line da sociedade sobre as mensagens postadas pelas TVs comunitárias em plataformas web, tais como respectivos sites ou blogs, fanpages (páginas do Facebook) e canais no YouTube, também considerando a relação das temáticas com a comunidade local.

Como recorte, consideramos duas TVs comunitárias: Caxias TV Comunitária, que atua no município de Duque de Caxias, por sua constante atualização de mensagens nas mídias sociais; e a TV Comunitária de Niterói, pela constante luta junto às autoridades locais para que o canal possa ser transmitido conforme a proposta do Canal da Cidadania. 
Neste último caso, no entanto, os representantes pró-canal comunitário sinalizam que as forças políticas parecem dificultar essa transição, sendo necessário pressionar a Prefeitura de Niterói a emitir o requerimento junto ao Ministério das Comunicações, solicitando espaço para as duas faixas de programação geridas pelas organizações sociais comunitárias.

A TV Comunitária de Niterói, que teve suas atividades iniciadas em 1999 por intermédio da organização de trabalhadores locais, mantém-se ativa até os dias atuais por intermédio de ações alternativas de comunicação. Apesar de sua interrupção, foi relançada em 15 de novembro de 2010. O canal possui dois perfis criados no Facebook e um no YouTube. No entanto, essas plataformas encontram-se defasada e sem atualizações.

A fanpage, com o nome TV Comunitária de Niterói, tem 302 seguidores, e sua última postagem ocorreu em 26 de janeiro de 2015. Já o outro perfil, denominado Canal da Cidadania de Niterói, tem 379 fãs, sendo que o último post ocorreu em 29 de junho de 2015. A criação desta última página representa mais um esforço em reunir entidades, sociedade e ONGs interessadas na condução do projeto Canal da Cidadania em Niterói; porém a falta de atualização das páginas pode indicar o enfraquecimento das mobilizações pró-TV comunitária no município em questão. A frequência das postagens não é regular em nenhuma das duas páginas, e as mensagens muitas vezes estavam atreladas à mobilização política, com reduzida interatividade no que diz respeito a "curtidas", além de uma quantidade média ou nula de comentários e compartilhamentos.

Fato semelhante ocorre com o perfil criado no YouTube, que está há sete meses sem atualização, sendo que há 91 seguidores inscritos. No campo para apresentação, a TV Comunitária de Niterói é descrita de modo simples, sem indicar a possibilidade de contato por meio do Facebook e nem mesmo como sintonizar o canal através da Net. A mensagem é curta e politizada: "TV Livre! Viva a TV Comunitária”. Nesse espaço, constam cinquenta vídeos disponíveis cujos conteúdos refletem o posicionamento dos posts realizados no Facebook: reportagens do tipo denúncia sobre política e acompanhamento de sessões de câmaras, protestos, dentre outros. A partir dessa amostra, comentários de possíveis espectadores não foram localizados no canal da TV Comunitária de Niterói disponível na plataforma do YouTube, e os vídeos não possuem número consistente de visualizações, o que indica repercussão e interação reduzidas também nesse espaço.

Ainda com relação ao conteúdo, percebemos pouca participação/aparição da população local diante das câmeras, assim como o indicativo de que as contribuições com o desenvolvimento de vídeos são isoladas - um exemplo seria o vídeo gravado em 2013 por adolescentes que perderam suas casas em virtude do desmoronamento do Morro do Bumba, em abril de 2010. A TV Comunitária de Niterói postou no canal do YouTube 
dois vídeos trazendo à memória os aniversários do desastre nas respectivas datas: três anos (aproximadamente sete minutos de conteúdo audiovisual, com 234 visualizações) ${ }^{5}$, e quatro anos (cerca de cinco minutos ${ }^{6}$ de vídeo, com 163 visualizações); sendo que a lembrança de três anos foi aquela publicada como registro dos próprios desabrigados. Em 2015, quando o incidente completou cinco anos e a população ainda se encontrava sem moradia fixa e sem perspectiva de melhoria, nenhuma mensagem desse canal sobre o tema foi localizada na internet.

Com relação à Caxias TV Comunitária, fundada em 2013, observamos que o uso das mídias sociais é mais frequente, estando os canais criados ativos (ou atualizados). A emissora é parte da iniciativa de estudantes que se mobilizaram para colocar em prática atividades laboratoriais de cursos ministrados sobre comunicação e usos digitais. Assim, o canal do YouTube conta com 232 inscritos e 62 vídeos postados, com destaque para jogos e treinos de futebol dos times locais. No entanto, diferente da TV Comunitária de Niterói, esse canal faz uma apresentação mais esclarecedora com o seguinte texto no YouTube: "é um canal local da cidade de Duque de Caxias no Rio de Janeiro. Somos constituídos por uma associação de entidades com fins não econômicos que procuram promover a cultura, cidadania e a história local visando o desenvolvimento do cidadão como seu principal objetivo! Contamos com alguns amigos e colaboradores, mas queremos você também fazendo parte da família Caxias TV Comunitária!"

A emissora também tem um site (caxiastv.com), e sua fanpage no Facebook tem 2.138 seguidores. Dentre as mensagens postadas, percebemos maior diversidade de objetivos, que vão desde informes e denúncias à divulgação de eventos culturais. Ou seja, neste caso, a comunicação é um veículo para prestação de serviço junto à população local. Nesses espaços, o canal convida insistentemente a comunidade a contribuir com sua programação, sobretudo com o jornal. Além dos espaços mencionados, é disponibilizado um número de telefone e possibilidade de contato através do aplicativo WhatsApp, o que indica não somente maior domínio sobre o uso de NTICs, mas também maior abertura para comunicação dialógica. Porém, apesar dos esforços observados, se a participação pode ser percebida através do Facebook com "curtidas" das mensagens, o mesmo não ocorre com o YouTube. Assim, esse canal parece estar melhor inserido no ambiente on-line, buscando aproveitar esses espaços criados para promover o canal e se comunicar com a população. Pelos dados coletados, também é válido comentar que, apesar das dificuldades e restrições peculiares do segmento de comunicação comunitária, os conteúdos da Caxias TV Comunitária apresentam estética, organização e roteiros nitidamente baseados

5 Disponível em: $<$ https://www.youtube.com/watch?v=KHlhO834XKo $>$.

6 Disponível em: $<$ https://www.youtube.com/watch?v=3E8RgQ5UcmU $>$. 
nas construções que predominam nas mídias comerciais. E embora os conteúdos sejam pautados por acontecimentos locais, ainda merece maior atenção o estímulo ao debate, à desconstrução dos fatos, ao olhar crítico e ao desenvolvimento de comunicação de fato alternativa e menos utilitarista.

Apesar das realidades locais diversas, das peculiaridades nas formas de se comunicar e dos distintos processos históricos de fundação, observamos que ambas TVs comunitárias possuem envolvimento reduzido da população com as postagens - quase nulo, tomando como referência o número de "curtidas", comentários e compartilhamentos. Esses últimos são escassos e pouco frequentes, sendo úteis muitas vezes para convocar outro internauta a ler o post. Outro fato relevante é que os vídeos são postados exclusivamente no YouTube e na íntegra, sem corte e edições. Além disso, posts com vídeos nas respectivas fanpages são raros - o que indica a contramão dos movimentos observados com a ampliação do consumo de vídeos na internet.

Portanto, o cenário atual revela um espaço limitado de expressão pela comunidade nas plataformas sociais analisadas. Para esses casos, a ausência de envolvimento e do vestígio de atividades aparentes pode gerar conclusões precipitadas sobre a passividade da comunidade com relação às iniciativas comunitárias de TV. Um estudo complementar in loco deve ser realizado para avaliar as relações sociais contruidas presencialmente com a comunicação comunitária.

No entanto, mesmo sob cisrcunstâncias distintas de financiamento, cabe consideramos os espaços de relacionamento construídos por ONGs junto às comunidades com o uso de NTICs. Por meio de um trabalho etnográfico realizado em 2007 com instituições não governamentais atuantes na Baixada Fluminense, Rio de Janeiro, Enne (2008) relata que o ponto em comum entre as ONGs analisadas é a política de atuação. Para tanto, há o reconhecimento de que o uso das NTICs e a relação com a mídia são mediações inevitáveis para estimular construções sociais e propiciar o empoderamento da população local. Logo, diferentes estratégias de comunicação são utilizadas, viabilizando a criação de produtos como sites, rádios, fanzines, murais etc.

São muitos os esforços, tanto institucionais quanto originados de iniciativas dos próprios jovens, para gerar novas apropriações e usos dos meios de comunicação e das mais diversas tecnologias, visando à produção, à circulação e ao consumo de produtos e informações [que permitam, dentre outros objetivos, democratizar o acesso às mesmas, criar canais para a livre expressão de ideias e opiniões, gerar formas de intervenção na esfera pública e legitimar a fala de determinados sujeitos sociais frequentemente excluídos dos espaços tradicionais, ocupados pelas grandes mídias. (ENNE, 2008, p. 195) 
Essa observação indica que a prática comunicacional da população para desenvolver TVs comunitárias deve ser objeto de análise continuada. É preciso investigar quais fatores influenciam na ausência de engajamento e se a falta de recursos econômicos pode ser fator determinante. As instituições avaliadas por Enne (2008), quais sejam: Centro de Integração Social Amigos da Nova Era (Cisane), Movimento Enraizados, Projeto Circo Baixada e Centro de Criação de Imagem Popular (Cecip) se mobilizam em torno de atividades que capacitam e colocam o sujeito social no centro dos projetos.

Diante do exposto, compreendemos que a inserção na, para a e através da comunidade possibilita que os indivíduos locais exerçam sua criatividade e se expressem de diferentes formas, com elementos mediadores que viabilizam o engajamento e a construção social de uma realidade mais justa, em que o direito à comunicação é garantido e ratificado com a apropriação de produtos simbólicos.

Para tanto, investigações aprofundadas parecem úteis como perspectivas a serem confirmadas por meio de observação também presencial e realização de entrevistas. No entanto, no atual contexto de desenvolvimento tecnológico, evolução das NTICs e apropriação social dos meios, entende-se que a reduzida interação dos internautas nessas mídias sociais geridas pelos canais comunitários possa ser um indício do que também ocorre com a radiodifusão.

\section{Construção de esfera pública pela comunicação comunitária}

A observação virtual apresentada teve como perspectiva a potencial "sistematização da comunicação pública como espaço plural para a intervenção do cidadão no debate de questões de interesse público" (MATOS, 2009, p. 47) e a garantia de aplicação de uma "política pública para a democratização do saber" (Ibid., p. 56). Assim, avaliamos a função política da TV comunitária na ocupação das mídias sociais como garantia de:

Livre participação de todos os interessados (possibilidade de um alargamento ilimitado do público), livre discussão de temas e assuntos (laicização da política e da cultura em geral) e igualdade de estatuto de todos os participantes (a sua competência é reconhecida em função da validade dos argumentos produzidos). (ESTEVES, 2004, p. 138)

Sabe-se que há negligências nas abordagens que situam comportamento e/ou tecnologia como eixo principal do estudo dos meios. Esses elementos são muitas vezes citados como protagonistas propulsores da indústria da mídia, mas não devem ser o alvo principal das análises. Assim, voltaremos nossos esforços para as perspectivas de potencial 
envolvimento do público internauta e a identificação do modo como as mensagens são disseminadas nas mídias sociais pela TV comunitária na era da comunicação em rede.

Com a crescente disseminação de conteúdos pela internet a partir de iniciativas dos chamados prosumers, uma linguagem diferenciada é instaurada. As trocas desenvolvidas e disseminadas através da internet apontam que a estética nem sempre é fator determinante para atrair a atenção dos internautas. Vídeos caseiros com poucos recursos tecnológicos e sem orçamento são comentados, adquirem visibilidade e repercutem de modo exponencial.

Apesar do acesso à internet ainda apresentar restrições e se caracterizar como espaço seletivo pela ausência de acesso a todos, a comunicação comunitária pode ser um porta-voz da comunidade, reproduzindo conteúdos em outros espaços, além do espectro radiodifusor. Assim, o uso da internet com sites, canais de vídeos, microblogs, blogs, redes sociais, entre outros dispositivos, podem se caracterizar como lugares de disputa social, tornando-se essencial sua apropriação pelos movimentos sociais, principalmente aqueles cujos objetivos visam a descentralização dos meios de comunicação, para potencializar a participação da comunidade local.

Sabemos que nem sempre o que é divulgado representa interesse público, uma vez que a diversidade de populações com seus interesses individuais são entrelaçados com as ações dos atores sociais e suas perspectivas coletivas. No entanto, o que diferencia as nuances de uma comunicação pública mais próxima do consenso, pautada pela garantia ética e pelo compromisso com a justiça, são as oportunidades de debate e reflexão. Logo, a comunicação pública comunitária pode ser capaz de apresentar os diferentes ângulos e enquadramentos dos fatos, propiciando a construção de debates críticos e o envolvimento da sociedade através de recursos tecnológicos cabíveis e apropriação dos espaços midiáticos disponíveis.

Dessa forma, a tecnologia e seus recursos devem ser considerados nas estratégias de gestão e produção da comunicação comunitária. A convergência e a mobilidade, assim como as redes sociais, devem ser inseridas de modo complementar aos espectros hertziano e digital, tal como vem sendo conduzidas pela mídia privada. Isso ratifica a importância das disputas locais pelo uso democrático dos canais comunitários em DTV ${ }^{7}$, espaço para a representação cotidiana dos cidadãos. Nessa perspectiva, entende-se que a tecnologia pode ser um relevante aliado, mas está longe de se consolidar como libertadora e liberadora de uma esfera pública horizontal e dialógica.

\section{Digital TV.}


Embora não necessariamente dependente, a configuração do espaço público pode ser mediada pela tecnologia e pelas mídias. Nesse ponto, é válido considerarmos se as mídias sociais são capazes de prover esfera pública horizontal e dialógica, avaliando possíveis contribuições para o desempenho das iniciativas de radiodifusão comunitária. A apropriação dos espaços disponíveis, desde mídias sociais à radiodifusão, tem relevância justamente por percorrer um caminho complementar e dinâmico de intervenção local no cenário de concentração midiática já consolidado, cuja origem pode ser identificada através da mudança estrutural da esfera pública exposta por Habermas (2003). No entanto, todos os resultados dependerão do contexto que será delineado a partir das mobilizações sociais que possam ressignificar as construções históricas e culturais. De fato, o cenário poderá continuar dificultoso caso não exista o apoio programado do Estado através de ações político-econômicas para fortalecimento do espaço social no local.

Esteves (2004, p. 151-153) propõe que a configuração do espaço público seja vista como um projeto inacabado, em contínuo desenvolvimento e transformação. Por essa vertente, os elementos que compõem o espaço público da atualidade tornam inviáveis as comparações com o de outrora, que se complexificou, adquirindo novos contornos sociais, políticos e tecnológicos. Critica, portanto, a percepção apocalíptica de teóricos que desconsideram qualquer potencial "revitalização do espaço público moderno", mesmo que proporcionada pelas inovações tecnológicas e pela consequente virtualidade.

Logo, cabe a nós, pesquisadores, estudiosos e ativistas, identificar e fortalecer as contribuições da radiodifusão comunitária para a constituição de espaço público, que, fomentado pela pluralidade de esferas e de públicos, e pelas TICs, garanta a legitimidade do envolvimento cívico, a (re)politização e, portanto, a deliberação de temas constituintes do interesse público.

Nesse caso, o papel da comunicação pública comunitária é reforçado para garantir espaço à diversidade de vozes e ao diálogo, independentemente do dispositivo, plataforma ou meio utilizado; ou seja, deve estar preparada para atuar nos diversos espaços públicos que se configuram. Portanto, se não houver um esforço de mobilizações sociais para ir de encontro aos modelos hegemônicos, apresentando outras opções à sociedade, não será a tecnologia que por si só o fará. Desse modo, no ambiente caracterizado pela ausência de regulamentação e de estruturação de processos, devemos buscar menor dependência tecnológica, mas orientação por transformações sociais, fruto de constantes lutas.

De modo entusiasta, Castells (2012) avalia que as redes sociais na internet se constituem em espaços de autonomia, muito além do controle de governos e empresas que monopolizam os canais de comunicação como alicerces de seu poder. Contudo, essa 
ausência de poder dos interesses privados e de controle governamental sobre os espaços públicos instituídos pelas redes virtuais é questionável. Esteves (2004) aponta que a atual despolitização do espaço público - neste caso podemos também considerar as redes virtuais - envolve mecanismos de controle e processos complexos que garantem ao Estado proximidade e poder sobre esses "lugares". Incluiríamos as forças exercidas pelo mercado para, mais do que ocupar, intervir na sua construção e no fornecimento de ferramentas tecnológicas e estruturais essenciais. Logo, embora atuante nas redes, a sociedade pode mostrar-se afastada politicamente do espaço público, sobretudo quando ocorre o desconhecimento do potencial desse ambiente como legitimador do interesse público.

Em todo caso, as mídias sociais podem se configurar como espaços de mobilização social e representam oportunidade para a comunicação comunitária fortalecer sua relação com a comunidade local e com toda a sociedade. Nesse aspecto, as inovações tecnológicas e o uso de TICs potencializam a influência dos meios sobre as esferas política, social, econômica e cultural garantindo síntese de níveis de comunicação até então bem delimitados - o global confunde-se com o local.

Nessa circunstância, a comunicação comunitária pode ocupar os espaços virtuais e fortalecer sua atuação no espectro radiodifusor ou digital. As ações em prol da democratização da comunicação e a respectiva instituição de sistema público podem exercer tensão e viabilizar a construção de espaço público dialógico e participativo. No entanto, é preciso ir além da luta pela apropriação do espectro de radiodifusão e sua garantia de existência - ou seja, ocupar espaços proporcionados pela tecnologia e fortalecer a convergência. Devemos compreender a dinâmica da comunicação pública comunitária através das diferentes plataformas, acompanhando o cenário de convergência midiática, porém não minimizando a relevância e força da radiodifusão.

\section{Conclusão}

Este estudo abordou o uso das mídias sociais pelas iniciativas comunitárias de TV, identificando as vantagens e limitações de sua contribuição para a constituição de esfera pública política. Em tempos de convergência transmídia, as plataformas sociais devem ser utilizadas de modo complementar à atuação nos meios tradicionais com intuito de articular a sociedade em prol do fortalecimento das iniciativas comunitárias de TV. Dessa forma, a atuação conjunta nos diferentes espaços midiáticos permite o estabelecimento de dinâmicas como resistência para a constituição de agenda democrática, pautada nas construções culturais e simbólicas populares.

Como exposto, a radiodifusão comunitária vem sendo usualmente pensada - por seus realizadores e organizações sociais que a suportam, bem como por pesquisadores da 
área - a partir das práticas e processos em seus locais de atuação e seus desafios cotidianos. Porém, a deslegitimação crescente dessas atividades se dá pelos mecanismos regulatórios que as inibem, da recorrente desqualificação por parte da mídia convencional, da preferência por espaços que não enfrentam esses impasses, como a web ou as ruas e, por fim, através das recentes transformações tecnológicas, que configuram tempos de convergência transmidiática em ambientes multiplataforma.

Logo, a própria afirmação da condição periférica e à margem das iniciativas de comunicação comunitária acaba reforçando sua fragilidade e suas descontinuidades, viabilizando a apologia de seus méritos por suas limitações estruturais, mas desconstruindo sua legitimidade do ponto de vista da formulação e implementação de políticas públicas que assimilem a importância do setor.

A formação de rede entre emissoras comunitárias de rádio e TV é também um aspecto regulatório importante, pois reconhece potencial de integração entre iniciativas comuns ou mesmo a possibilidade tecnológica de transmissão de conteúdos relevantes para a população, para além das comunidades locais. Se por um lado esse mecanismo pode ser acionado e reconhecido independentemente do alcance determinado pelos limites das potências estabelecidos em lei, por outro, garantiria ao conjunto de iniciativas comunitárias a possibilidade de alcance mais amplo de seus conteúdos de interesse. Vale lembrar que esse recurso geralmente é delimitado quanto às ocasiões em que pode ser acionado e que se faz necessário em caráter eventual, justamente para não configurar um modo extraoficial de ampliação prática de sinal.

Nesse mesmo caminho encontra-se a possibilidade de veiculação de conteúdos pela web ou mesmo a criação de web rádios ou web TV/canais do YouTube e serviços similares, como os mais recentes serviços de transmissão ao vivo de eventos; a despeito de uma regulamentação que conceda a transmissão desses conteúdos, por se tratar de ambiente da internet e não uso de bem público, o que demandaria reconhecimento do Estado. Por outro lado, esses serviços são pagos e pressupõem relativo conhecimento e mobilização de infraestrutura adicional às emissoras, o que implica em custos que poderiam ser mantidos mediante convênios, reeditando as articulações entre grupos populares e de apoio dos anos 1970 e 1980.

A despeito das facilidades apresentadas, cabe compreender que o ambiente da internet ainda se apresenta como fragmentado e limitado, do ponto de vista da mobilização do conjunto da sociedade. Se é possível compreender que mudou o ambiente em torno do qual rádios e TVs comunitárias são acolhidas como relevantes práticas sociais em seus locais de atuação, é pertinente considerar suas contribuições específicas dentro de um cenário de convergência tecnológica e de plataformas midiáticas que significam 
importantes territórios de conformação da agenda política e de opinião pública no campo do simbólico e do cultural.

É possível, no entanto, pensar esse ambiente num contexto contemporâneo de convergência transmidiática de ambientes multiplataforma, no qual a relação entre meios massivos e em rede seja pensada como complementar, bem como a das comunidades locais e a população em geral; compreendendo a pluralidade e a diversidade existentes, ingredientes fundamentais para a afirmação da cidadania. E, nesse sentido, é possível o reencontro com os princípios estabelecidos pela Amarc, especialmente no tocante às questões relacionadas ao acesso tecnológico e $\grave{a}$ inclusão digital.

Nesse novo cenário, cabe considerar a possibilidade de implementação de redes mútuas de contribuição multiescala e de convergência transmídia, nos quais iniciativas comunitárias de radiodifusão usariam de modo complementar as mídias sociais e seriam articuladas com atividades elaboradas e executadas a partir da web, compreendendo, no conjunto dessas interações, que se trata de defender e afirmar a importância de todos os territórios de atuação da sociedade que se apropria dos meios e veículos de comunicação em prol da elaboração de práticas democráticas que a afirmem como direito humano inalienável.

\section{Referências}

ASOCIACIÓN MUNDIAL DE RADIOS COMUNITARIAS. Principios para garantizar la diversidade y el pluralismo en la radiodifusión y los servicios de comunicación audiovisual. 2010. Disponível em: <http://bit.ly/2pOdCjK>. Acesso em: 23 ago. 2012.

BRASIL. Constituição da República Federativa do Brasil de 1988. Artigo 223. Diário Oficial da União, Brasília, DF, 5 out. 1988.

CASTELLS, M. Redes de indignação e esperança: movimentos sociais na era da internet. Tradução de Carlos Alberto Medeiros. Rio de Janeiro: Zahar, 2012.

ENNE, A. Práticas midiáticas e disputas por hegemonia: reflexões a partir de estudos de caso na Baixada Fluminense. In: COUTINHO, E. (Org.). Comunicação e contra-hegemonia. Rio de Janeiro: UFRJ, 2008. p. 195-214.

ESTEVES, J. Espaço público. In: RUBIM, A. (Org.). Comunicação e política: conceitos e abordagens. Salvador: UFBA, 2004. Disponível em: <http://bit.ly/2rjenSV>. Acesso em: 22 dez. 2015.

HABERMAS, J. Mudança estrutural da esfera pública: investigações quanto a uma categoria da sociedade burguesa. Tradução de Flávio R. Kothe. Rio de Janeiro: Tempo Brasileiro, 2003.

KERN EUROPEAN AFFAIRS (KEA). The state of community media in the European Union. Brussels: European Parliament, 2007. Disponível em: <http://bit.ly/2qoven6>. Acesso em: 15 maio 2017. 
MATOS, H. Comunicação pública, esfera pública e capital social. In: DUARTE, J. (Org.). Comunicação pública: Estado, mercado, sociedade e interesse público. 2. ed. São Paulo: Atlas, 2009.

PERUZZO, C. K. Revisitando os conceitos de comunicação popular, alternativa e comunitária. In: CONGRESSO BRASILEIRO DE CIÊNCIAS DA COMPUTAÇÃO, 19., 2006, Brasília, DF. Anais... Brasília, DF: Universidade de Brasília, 2006. Disponível em: <http://bit.ly/2rjlsDb>. Acesso em: 15 maio 2017.

RAMOS, M. C. Sobre a importância de repensar e renovar a idéia de sociedade civil. In: RAMOS, M. C.; SANTOS, S. Politicas de comunicação: buscas teóricas e práticas. São Paulo: Paulus, 2007.

SANTORO, L. F. A imagem nas mãos: o vídeo popular no Brasil. São Paulo: Summus, 1989.

MACBRIDE, S. et al. Uno solo mundo, voces múltiples - comunicación y información en nuestro tiempo. Belgrado: Unesco, 1980. Disponível em: <http://bit.ly/1khDkaZ>. Acesso em: 12 nov. 2009. 